\title{
Using an Al-Cu binary alloy to compare processing by multi-axial compression and high-pressure torsion
}

\author{
Xiaochang $\mathrm{Xu}^{\mathrm{a}, \mathrm{b}}$, Qi Zhang ${ }^{\mathrm{a}}$, Nan $\mathrm{Hu}^{\mathrm{a}, \mathrm{c}}$, Yi Huang ${ }^{\mathrm{c}, *}$, Terence G. Langdon ${ }^{\mathrm{c}, \mathrm{d}}$ \\ a School of Materials Science and Engineering, Central South University, Changsha 410083, China \\ ${ }^{\mathrm{b}}$ Key Laboratory of Nonferrous Metal Materials Science and Engineering, Ministry of Education, Central South University, Changsha 410083, China \\ ${ }^{\mathrm{c}}$ Materials Research Group, Faculty of Engineering and the Environment, University of Southampton, Southampton SO17 1BJ, UK \\ d Departments of Aerospace E Mechanical Engineering and Materials Science, University of Southern California, Los Angeles, CA 90089-1453, USA
}

\section{A R T I C L E I N F O}

\section{Article history:}

Received 11 August 2013

Received in revised form

30 August 2013

Accepted 2 September 2013

Available online 8 September 2013

\section{Keywords:}

$\mathrm{Al}-\mathrm{Cu}$ alloy

High-pressure torsion

Homogeneity

Multi-axial compression

Ultrafine grains

\begin{abstract}
A B S T R A C T
An $\mathrm{Al}-4 \% \mathrm{Cu}$ alloy was selected as a model material in order to compare two different procedures for imposing severe plastic deformation: multi-axial compression (MAC) and high-pressure torsion (HPT). In MAC a compressive strain is applied to prismatic samples in a sequential order along three orthogonal directions and the process is repeated to large numbers of passes in order to attain high strains. In HPT a thin disk is held between anvils and subjected to a high applied pressure and concurrent torsional straining. The results show that HPT is the optimum procedure for producing a homogeneous ultrafinegrained material. Specifically, HPT is preferable because it produces materials having a larger degree of homogeneity and the equilibrium grain sizes are smaller and the Vickers microhardness values are higher than when processing by MAC.
\end{abstract}

(c) 2013 Elsevier B.V. All rights reserved.

\section{Introduction}

The processing of metals through the application of severe plastic deformation (SPD) has attracted much attention over the last decade because it provides an opportunity for achieving ultrafine-grained (UFG) materials having grain sizes within the submicrometer $(0.1-1.0 \mu \mathrm{m})$ or nanometer $(<100 \mathrm{~nm})$ range $[1,2]$. A significant advantage of SPD processing is that it provides procedures in which bulk solids are subjected to very high strains without incurring any significant change in their overall dimensions [3]. Several different methods of SPD processing are now available but the primary methods are equal-channel angular pressing (ECAP) [4], high-pressure torsion (HPT) [5], accumulative roll bonding (ARB) [6] and multi-directional forging [7]. To date, most attention has focused on ECAP and HPT and it is now well established that processing by HPT produces materials having smaller grain sizes than ECAP [8-10].

Conversely, only limited attention has been devoted to the processing of metals by multi-directional forging although this appears to be a simple and cost-effective method for the production of bulk UFG solids for use in industry. In this process as originally formulated, the material is subjected to a forging operation in which loading is performed in compression, the axis

\footnotetext{
* Corresponding author. Tel.: +44 2380594438; fax: +44 2380593016 .

E-mail address: Y.Huang@soton.ac.uk (Y. Huang).
}

of loading is changed periodically and there is no restraint on the outward flow of material. Specifically, the process involves applying straining to prismatic samples sequentially along three orthogonal directions in a procedure generally designated as $a b c$ deformation [11]. This process was used for detailed investigations of the properties induced in a Ti-6Al-4V alloy [11] and high purity oxygen-free $\mathrm{Cu}[12,13]$ but in practice the procedure has experimental limitations because it is necessary to machine or grind the samples after each straining in order to remove the barreling introduced by the compression.

Later, the general principles of this process were developed into the procedure of multi-axial compression (MAC) in which samples of $\mathrm{Cu}$ were contained within a channel die, there was a constraint on two of the four lateral sides of the sample and the processing operation was conducted without introducing any barreling on the faces used subsequently for the loading operation in the next pass so that it was not necessary to grind the faces between each separate straining [14]. The procedure of MAC has been used to investigate the properties of several materials including AA1100 [15], AA3104 [16] and AA6061 [17,18] aluminum alloys, Al-4.11\% $\mathrm{Cu}$ [19], Al-5.5\% Cu [20] and high purity Cu [19]. Nevertheless, only limited information is available at present comparing the properties and microstructures of samples processed by MAC and other SPD procedures. An early report attempted to compare MAC with ECAP and ARB by processing samples of an AA6061 alloy to similar strains using each procedure but the results were inconclusive and it was reported only that similar grain sizes of $<1.0 \mu \mathrm{m}$ were 
achieved using each process with similar values of hardness and similar tensile properties after processing [17]. More recently, experiments were reported on an $\mathrm{Al}-4.11 \% \mathrm{Cu}$ alloy using MAC and ECAP and it was reported that the hardness increased more rapidly with strain when using ECAP but there were no measurements of the grain sizes after processing [19]. Furthermore, there has been no attempt to date to compare MAC directly with HPT although it is known that HPT is especially effective in producing very small grain sizes.

Accordingly, the present investigation was initiated to provide a first detailed comparison between the microstructures produced by MAC and HPT with a special emphasis on the grain sizes and the levels of homogeneity achieved using these two techniques. The experiments were conducted using an $\mathrm{Al}-4 \% \mathrm{Cu}$ alloy where this material was selected because earlier experiments demonstrated the successful processing of $\mathrm{Al}-\mathrm{Cu}$ binary alloys when using MAC $[19,20]$ and ECAP [19].

\section{Experimental material and procedures}

Selected quantities of an aluminum of commercial purity (99.9\%) and an $\mathrm{Al}-52.3 \mathrm{wt} \% \mathrm{Cu}$ alloy were melted in a graphite crucible in an electrical resistance furnace at $1073 \mathrm{~K}$. The melt was maintained at $973 \mathrm{~K}$ for $10 \mathrm{~min}$ and then quickly and smoothly poured into a metal mold to give a cast $\mathrm{Al}-4 \mathrm{wt} \% \mathrm{Cu}$ binary alloy. The ingot was homogenized at $758 \mathrm{~K}$ for $24 \mathrm{~h}$ in air and then cut into rectangular prisms with dimensions of $10.0 \times 10.0 \times 15.0 \mathrm{~mm}^{3}$ for MAC processing or into rods with diameters of $10.0 \mathrm{~mm}$ and lengths of $8.0 \mathrm{~cm}$ for use in HPT processing. Following an earlier procedure [21], these samples were solution treated at $813 \mathrm{~K}$ for $2 \mathrm{~h}$ and then quenched in cold water and subsequently aged at $693 \mathrm{~K}$ for $2 \mathrm{~h}$ [19].

For processing by MAC, the rectangular prisms were initially compressed at room temperature (RT) through the various passes depicted schematically in Fig. 1 where this corresponds to the conventional $a b c$ deformation such that the shape of the prism after 3 passes is identical to the initial shape. Samples were processed up to a maximum number, $N$, of 15 passes. Subsequently, and in order to achieve high strains, MAC processing was conducted at a temperature of $373 \mathrm{~K}$ with intermediate annealing treatments for $10 \mathrm{~min}$ at $373 \mathrm{~K}$ up to a total of $N=35$ passes. For processing by HPT, the rods were sliced into disks with thicknesses of $\sim 1 \mathrm{~mm}$, the disks were polished to final thicknesses of $\sim 0.85 \mathrm{~mm}$ and then processing was accomplished using an HPT facility operating under quasi-constrained conditions in which the disk is held under an applied pressure between two massive anvils and there is a limited outward flow of material around the periphery of the disk during the processing [22,23]. A detailed

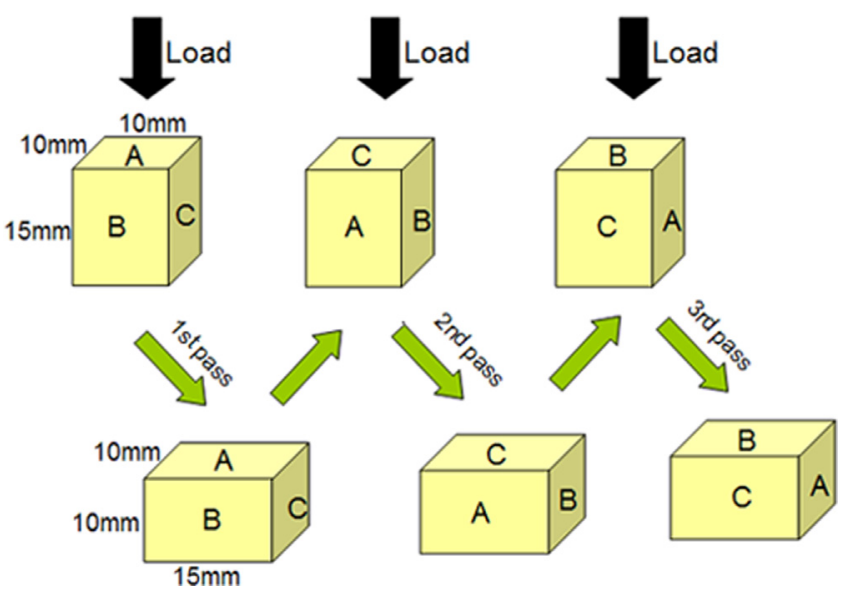

Fig. 1. Schematic illustration of the principles of MAC in $a b c$ deformation. description of the HPT processing procedure was given earlier [24] except that in the present experiments a molybdenum disulfide lubricant was not placed around the disk on the upper and lower anvils. The HPT processing was conducted at RT under an applied pressure of $5.0 \mathrm{GPa}$ using a rotational speed of $1 \mathrm{rpm}$ for different numbers of turns, $N$, up to a maximum of 9 turns.

The samples processed by MAC and HPT were evaluated in different ways as illustrated schematically in Fig. 2. For the MAC samples, the rectangular prisms were cut horizontally perpendicular to the axis of the last compression and at positions close to the central planes. Hardness measurements were recorded on these planes at the positions shown in Fig. 2(a) and samples were prepared for transmission electron microscopy (TEM) at the positions indicated in the central and peripheral regions. For the HPT disk shown in Fig. 2(b), hardness measurements were recorded along diameters of the samples and small disks were prepared for TEM observations at both the centers and near the edges of the disks. Hardness measurements were undertaken at the points indicated in Fig. 2 by mounting the samples, carefully polishing to a mirror-like surface and then recording values for the Vickers microhardness, Hv, using a Micro-DUROMAT4000 facility with a load of $100 \mathrm{~g}$ and a dwell time of $15 \mathrm{~s}$ for each indentation. It is apparent from Fig. 2 that the incremental spacings between the microhardness indentations are generally $1.0 \mathrm{~mm}$ for both the MAC and HPT samples. For MAC, the hardness measurements represent the average of three separate indentations recorded at the same distance from the center of the plane of sectioning along the longitudinal and transverse directions, respectively. For the HPT samples, the values of Hv were determined by taking the average of four separate measurements recorded along four different radii at the same distance from the center of each disk.

The internal microstructures were observed by TEM using a TECNAI-G2 20ST instrument operating at $200 \mathrm{kV}$. The disks for TEM were mechanically ground below $90 \mu \mathrm{m}$ and then electropolished with a solution of $30 \%$ nitric acid and $70 \%$ methanol at 10 $\mathrm{V}$ using an electrolyte maintained at a temperature below $-25^{\circ} \mathrm{C}$. Selected area electron diffraction (SAED) patterns were recorded using an aperture size of $1.0 \mu \mathrm{m}$.

\section{Experimental results}

In order to evaluate the microstructural inhomogeneities in samples processed by SPD, the most convenient approach is to take measurements of the local microhardness and then correlate a selected set of these hardness values with microstructural observations undertaken using TEM $[25,26]$. Following this approach, the microstructural evolution occurring in the $\mathrm{Al}-\mathrm{Cu}$ binary alloy is described in the following two sections when processing by MAC and HPT, respectively.

\subsection{Hardness and microstructural evolution during MAC processing}

The variation of the Vickers microhardness with the number of compression passes is shown in Fig. 3(a) for the central and edge regions of the specimens processed by MAC at room temperature where the values of hardness in the outer regions were determined by taking the averages of the longitudinal and transverse measurements at distances of $4 \mathrm{~mm}$ from the center. It is apparent that all of the microhardness values taken in the central regions of the rectangular prisms are higher than at the edge regions and for a condition of $N \approx 9$ passes both sets of measurements tend to reach saturation levels. The equivalent strain imposed in each pass in MAC is given by $\ln \left(h_{\mathrm{o}} / h\right)$ where $h_{\mathrm{o}}$ and $h$ are the initial height $(15 \mathrm{~mm})$ and final height $(10 \mathrm{~mm})$ of the samples, respectively [11]. This gives a strain of $\sim 0.4$ in every pass of MAC so that the 
a
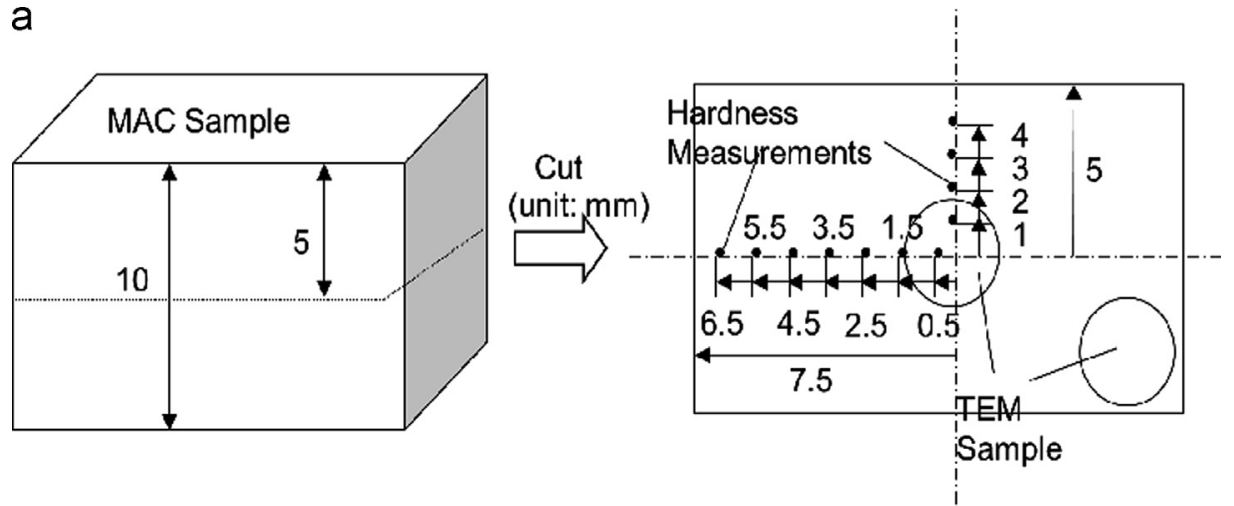

b

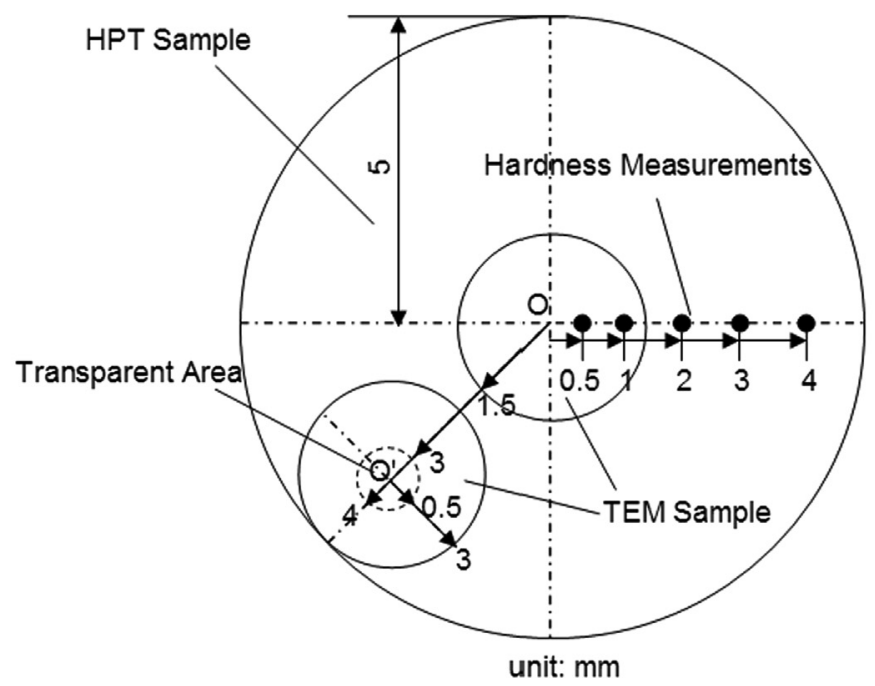

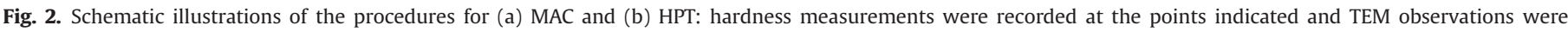
undertaken at the positions shown by the TEM samples.

strain imposed after 15 passes is $\sim 6$. In order to impose additional strains in MAC, the processing was conducted at a temperature of $373 \mathrm{~K}$ using intermediate annealing treatments for $10 \mathrm{~min}$ at 373 K. Fig. 3(b) shows the microhardness distributions along longitudinal and transverse directions for samples processed to 15 passes at RT and 35 passes at $373 \mathrm{~K}$. It is apparent that after 15 passes there is a non-uniform distribution of microhardness values across the sample with lower values at the edges for the longitudinal and transverse directions. Conversely, after 35 passes at $373 \mathrm{~K}$ the hardness values are lower because of the higher processing temperature but the inhomogeneity is removed and similar values of Hv are recorded at every position.

Representative micrographs were taken using TEM in order to determine the grain size distributions. Fig. 4 shows examples of the TEM images and the associated SAED patterns for the alloy processed by MAC through 9 passes at room temperature for (a) the central region and (b) in the edge region of the rectangular prism, where this processing condition has an imposed strain of 3.6. It is apparent from Fig. 4(a) that the microstructure in the central region is refined but very inhomogeneous. Measurements showed the minimum and maximum grain sizes in this region were $\sim 0.1$ and $\sim 1.0 \mu \mathrm{m}$, respectively, with an average grain size of $\sim 0.79 \mu \mathrm{m}$. At the edge region in Fig. 4(b), the microstructure contains a higher percentage of elongated grains and a higher dislocation density compared with the central region. Similar microstructures were reported earlier in an $\mathrm{Al}-1.7 \mathrm{at} \% \mathrm{Cu}$ alloy processed by ECAP through 5 passes using a channel angle of $90^{\circ}$ where the imposed strain was $\sim 5$ [27].
Micrographs are shown in Figs. 5 and 6 near the center and the edge, respectively, after 15 passes at room temperature. Near the center of the sample in Fig. 5 an area of reasonably equiaxed grains is shown in (a), a region of elongated grains in (b) and the sample in (c) was additionally annealed for $1 \mathrm{~h}$ at $473 \mathrm{~K}$. Near the edge in Fig. 6 a similar microstructure of equiaxed and elongated grains is shown in (a) and the microstructure in (b) was annealed for $1 \mathrm{~h}$ at $473 \mathrm{~K}$. It should be noted that similar arrays of equiaxed and elongated grains were reported earlier in high purity aluminum after processing by ECAP for 1 pass at room temperature [28]. In Figs. 5(a) and 6(a) the grains tend to be irregular in shape, there are large numbers of intragranular dislocations and the grain boundaries are wavy and poorly defined. These microstructural characteristics are similar to those reported in an $\mathrm{Al}-3 \% \mathrm{Mg}$ alloy after processing by ECAP $[29,30]$ and they are a consequence of the presence of a high fraction of non-equilibrium grain boundaries [31]. By contrast, following an annealing treatment at $473 \mathrm{~K}$ for $1 \mathrm{~h}$, the microstructures in Figs. 5(c) and 6(b) show grains that are reasonably equiaxed, there is a relatively low dislocation density and the average grain size is $\sim 0.59 \mu \mathrm{m}$.

These experimental results demonstrate that a large number of passes are needed, combined with an annealing treatment, in order to obtain reasonable microstructural homogeneity after processing by MAC. Fig. 7 shows examples of the microstructures achieved after processing by MAC through 35 passes at the higher temperature of $373 \mathrm{~K}$ : the central and edge regions are shown in (a) and (b) after 35 passes at $373 \mathrm{~K}$ and (c) and (d) show the microstructures in these two regions after an additional anneal for 
$1 \mathrm{~h}$ at $473 \mathrm{~K}$. In Fig. 7(a) and (b) both regions have a large fraction of equiaxed grains with an average size of $\sim 0.25 \mu \mathrm{m}$ and with the SAED patterns showing larger spreads of the diffraction spots than in Figs. 5(a) and 6(a) thereby indicating the presence of a

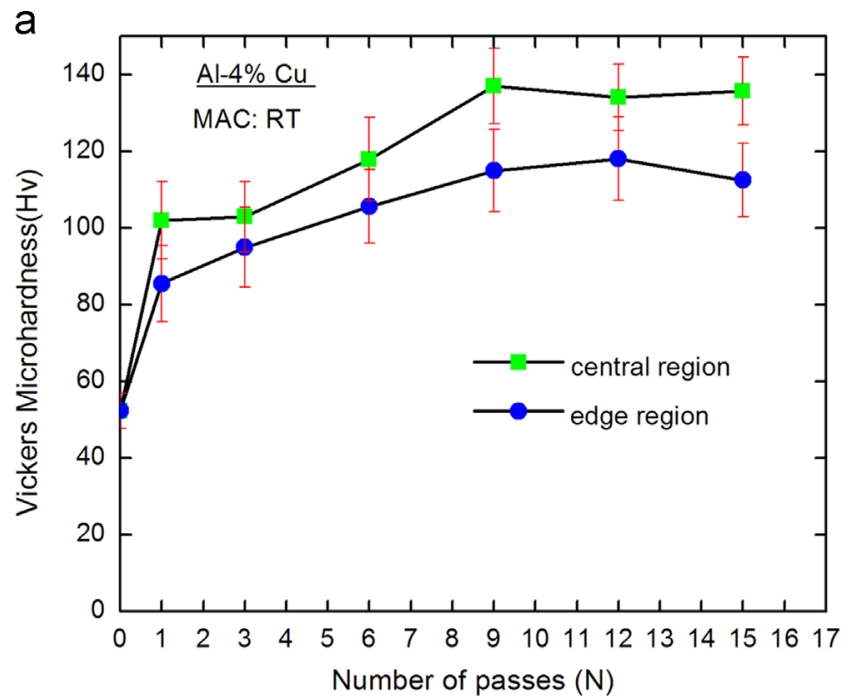

b

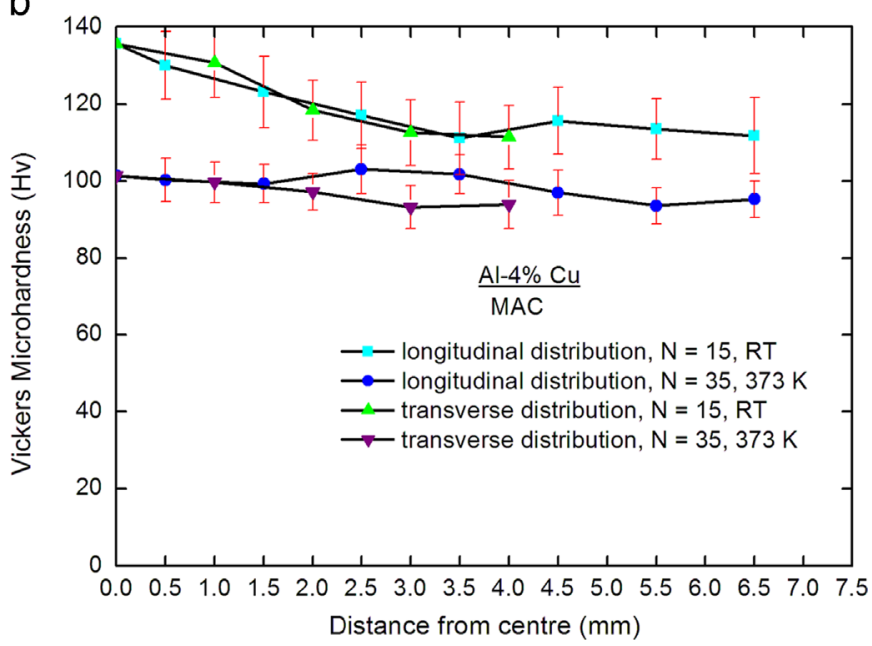

Fig. 3. (a) Average Vickers microhardness values for the central and edge regions of the prismatic specimens as a function of the numbers of passes in MAC; (b) Vickers microhardness distributions along longitudinal and transverse directions after processing by MAC through 15 passes at RT or 35 passes at $373 \mathrm{~K}$. reasonable fraction of high-angle grain boundaries. The corresponding annealed microstructures in Fig. 7(c) and (d) are reasonably homogeneous for both the central and edge regions and measurements gave average grain sizes of $\sim 0.5 \mu \mathrm{m}$.

\subsection{Hardness and microstructural evolution during HPT processing}

Processing by HPT produces significant strengthening as shown in Fig. 8 where values of the Vickers microhardness are plotted as a function of the distance from the center of the disk. The lower dashed line in Fig. 8 denotes the initial as-annealed condition at $\mathrm{Hv} \approx 54$ and experimental points are shown after processing through 1, 3, 5 and 9 turns under an applied pressure of 5.0 GPa. Two significant conclusions may be reached from inspection of Fig. 8. First, after 1 turn there is a non-uniform distribution of microhardness values across the sample diameter with significantly lower values in the center and high hardness values at the outer edge. Second, with increasing numbers of turns there is a significant increase in hardness in the central region of the disk but at the outer edge the hardness values remain essentially constant thereby confirming the development of a saturation condition. The tendency for lower hardness values to occur initially in the centers of the disks is consistent with earlier reports for several different materials including $\mathrm{Al}$ [32] and $\mathrm{Cu}$ [33] alloys and the gradual transition to a saturation hardness is also consistent with earlier observations $[34,35]$. In the present experiments, the data in Fig. 8 suggests that a reasonable level of homogeneity is achieved after 5 turns of HPT.

In order to evaluate the degree of homogeneity in the microstructures of the Al-Cu alloy, TEM micrographs and the corresponding SAED patterns are recorded in Fig. 9 where (a) and (b) are for $N=1$ turn in the center and outer region of the disk and (c) and (d) are for $N=5$ turns at the center and outer region, respectively. In Fig. 9(a) the central region has a coarse and illdefined microstructure and the presence of discrete spots in the SAED pattern denotes the presence of low-angle sub-boundaries. By contrast, at the outer region of the disk after 1 turn in Fig. 9 (b) there is an array of ultrafine grains with an average size of $\sim 0.25 \mu \mathrm{m}$ and the SAED pattern indicates the presence of many small grains having multiple orientations within the field of view. It is apparent from Fig. 8 that this condition corresponds essentially to a saturation in the value of the microhardness. The situation is different after 5 turns where there is a reasonably homogenous microstructure of equiaxed grains both in the central region in Fig. 9(c) and in the outer region in Fig. 9(d) and there is also a large spread in the diffraction spots of the SAED patterns indicating the presence of a high fraction of high-angle

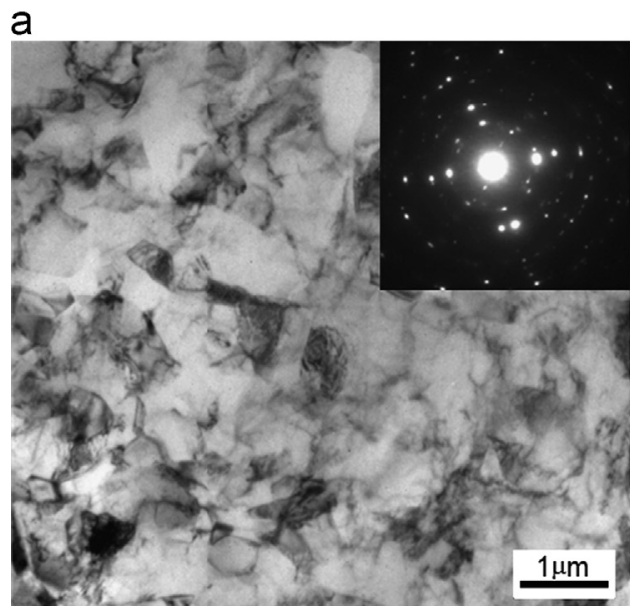

b

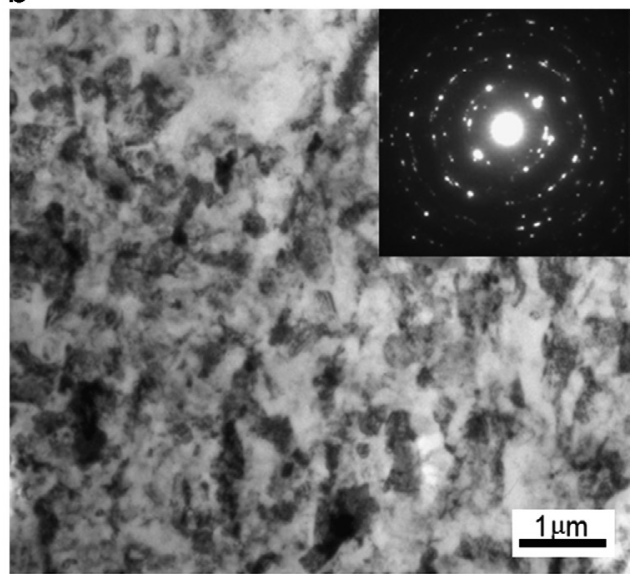

Fig. 4. Representative TEM microstructures after processing by MAC for 9 passes at room temperature in (a) the central region and (b) near the edge. 
a

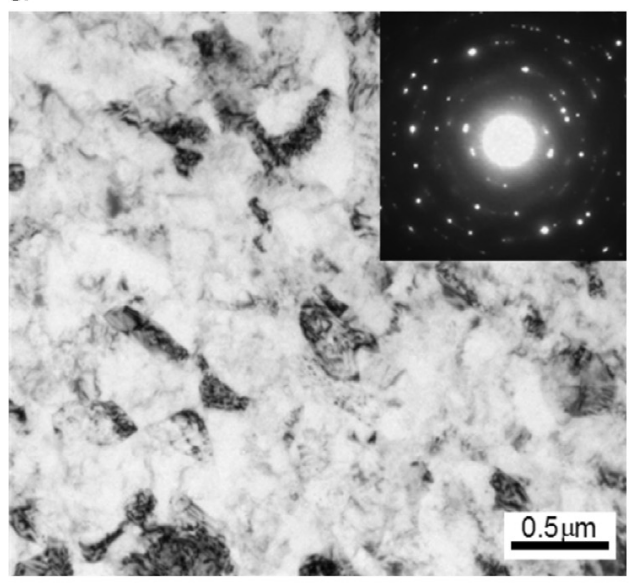

C

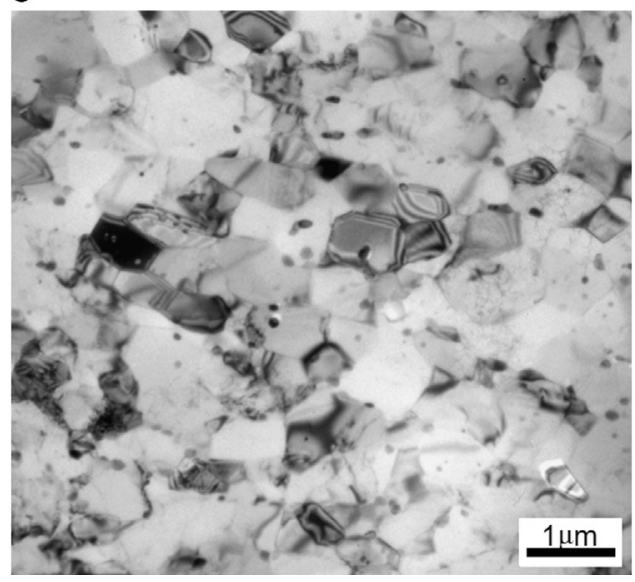

b

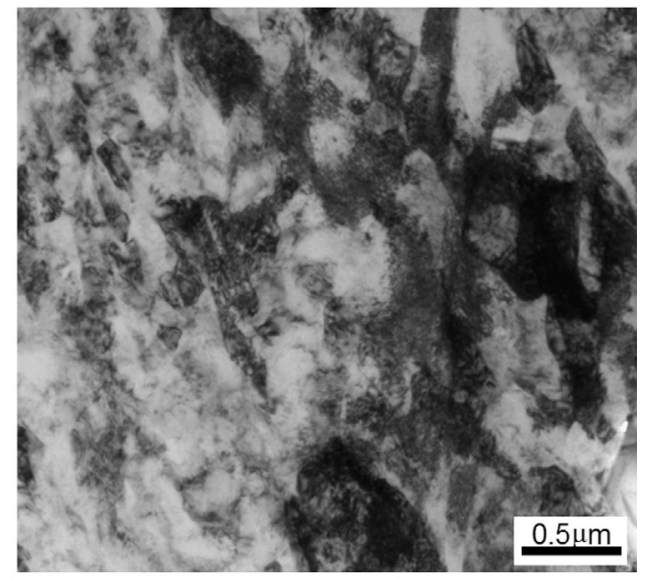

$0.5 \mu \mathrm{m}$

Fig. 5. Representative TEM microstructures of (a) equiaxed grains and (b) elongated grains in the central region of a sample processed by MAC through 15 passes at RT and (c) the corresponding annealed microstructure.

a

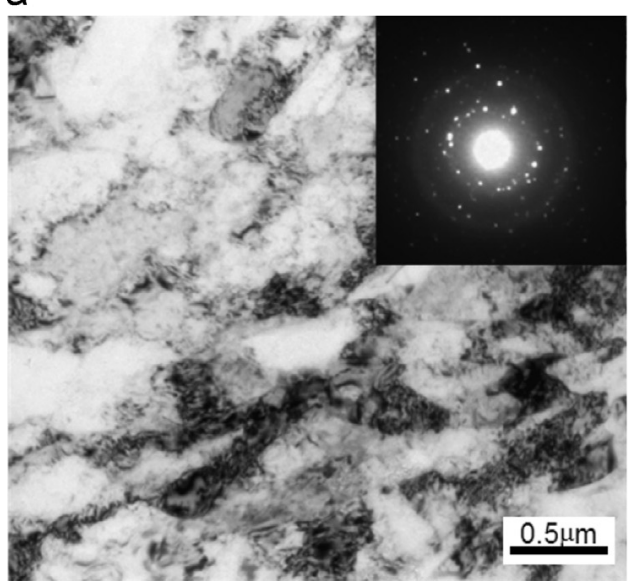

b

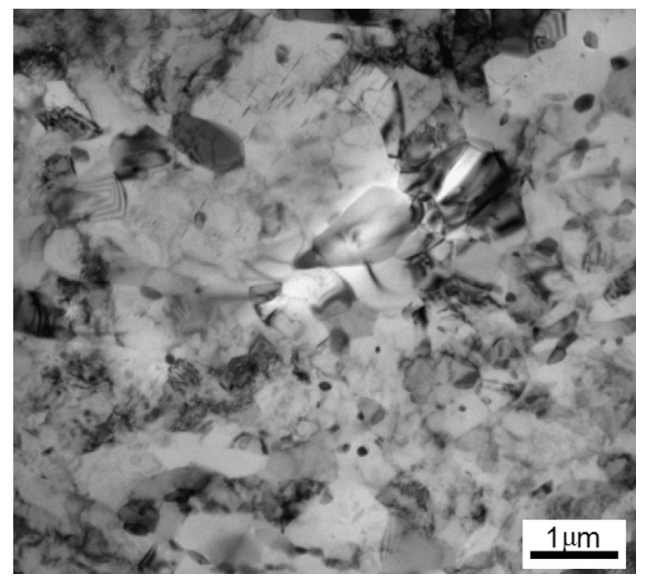

Fig. 6. Representative TEM microstructures (a) near the edge after MAC through 15 passes at RT and (b) the corresponding annealed microstructure.

boundaries. In this saturated condition, the microstructure is homogeneous and the average grain size was measured as $\sim 0.25 \mu \mathrm{m}$.

\section{Discussion}

The present results show that the processing of an $\mathrm{Al}-4 \% \mathrm{Cu}$ alloy by HPT leads to excellent homogeneity after 5 turns with an applied pressure of 5.0 GPa whereas in MAC the microstructure tends to be inhomogeneous except only after a very large number of passes as in Fig. 7 where the alloy was subjected to 35 passes. According to an analysis of plane multi-axial compression [36], the deformation models are inhomogeneous and unsteady with changes from simple shear to partial simple shear and to partial pure shear during every compression. Thus, the repeating of this non-uniform strain distribution necessitates a large number of compression steps in order to refine the total volume of the structure and to attain a relatively homogeneous microstructure. 
a

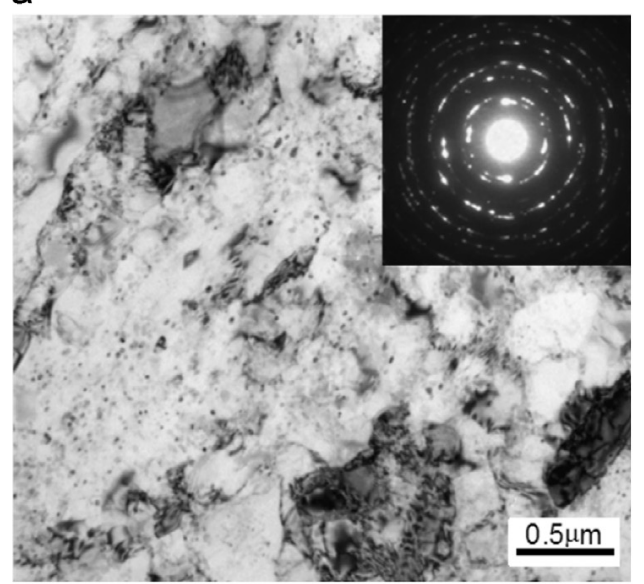

c

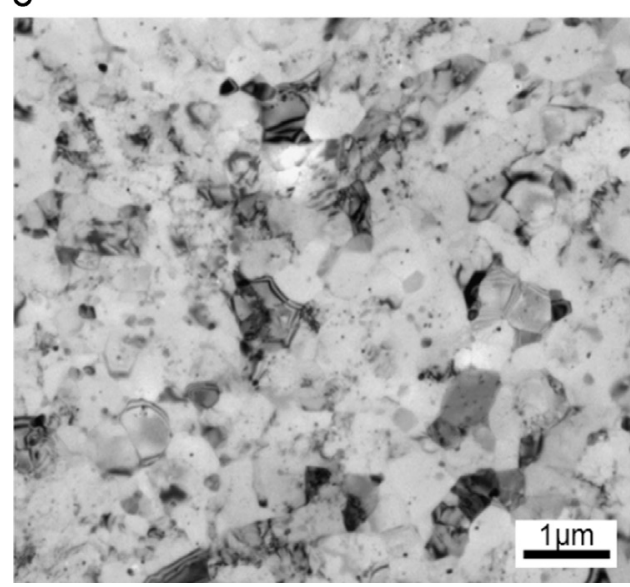

b

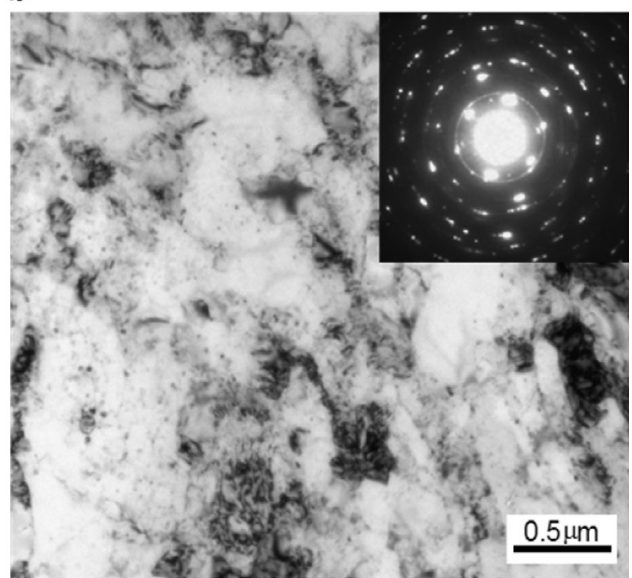

d

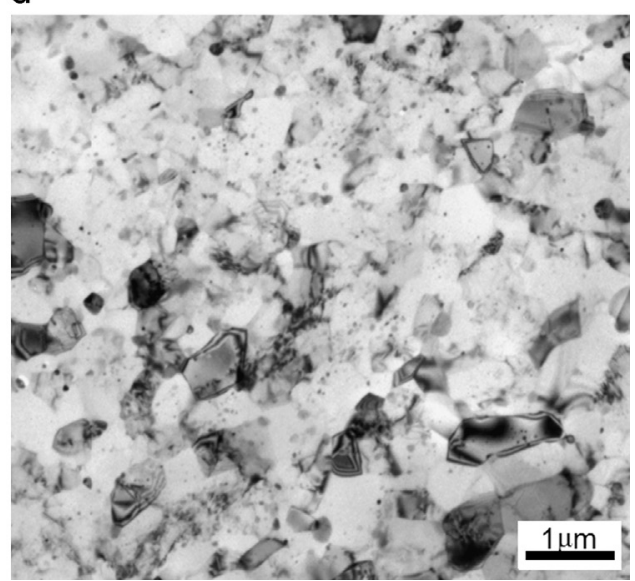

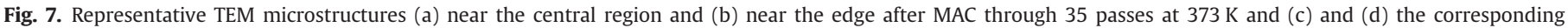
annealed microstructures.

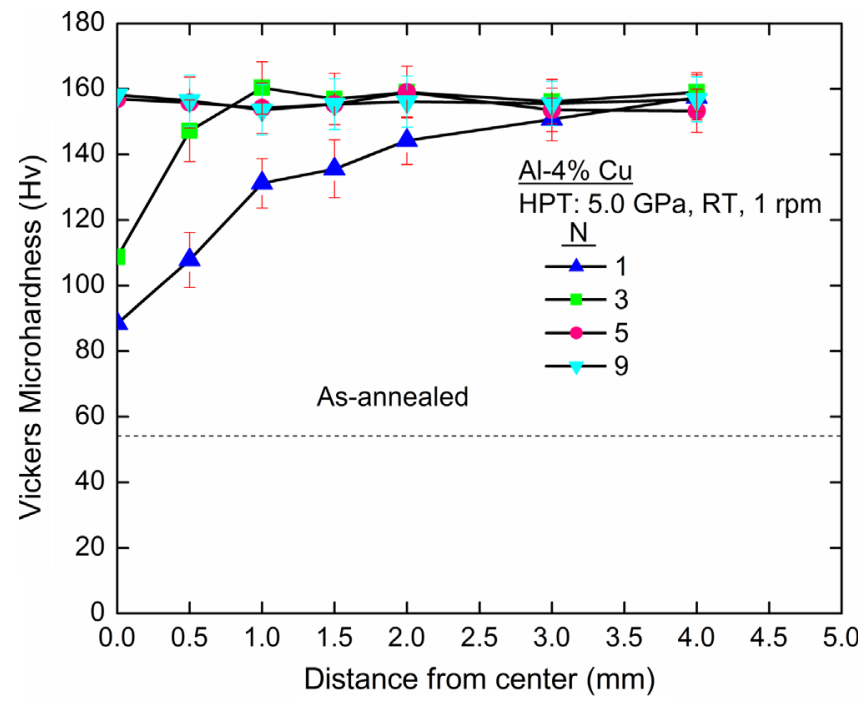

Fig. 8. Vickers microhardness as a function of distance from the centers of the disks after HPT at 5.0 GPa for different numbers of turns: the lower dashed line shows the as-annealed condition before HPT processing.

This conclusion is consistent with the microstructures shown in Figs. 5-7.

The mechanism of microstructural refinement in SPD processing appears to be the gradual subdivision of the initial coarse grains because of the interaction of subgrain bands [37] and this suggests the ultimate equilibrium grain size is controlled by the average width of these bands. Research on shear band formation during plane strain compression of an $\mathrm{Al}-3 \mathrm{wt} \% \mathrm{Cu}$ alloy suggests that the macroscopic shear bands are composed of finely-spaced sheared layers having widths of $\sim 0.1 \mu \mathrm{m}$ [38]. This is consistent with the widths of the smallest substructural features visible in the MAC samples in this investigation. Furthermore, it was proposed that shear bands are initiated in favorably oriented grains and then spread across each grain to ultimately fill the gauge section [38]. In the present experiments, the non-uniformity in the strain distributions during MAC processing produces microstructures in the Al-Cu alloy which are extremely inhomogeneous after 9 passes at room temperature as shown in Fig. 4.

An important requirement in these experiments is to make a direct comparison of the microstructures and hardness values in MAC and HPT after imposing similar values for the total strains. The relationship used to calculate the shear strain, $\gamma$, in HPT is of the form [39]

$\gamma=\frac{2 \pi N r}{h}$

where $r$ is the radial distance from the center of the disk and $h$ is the disk thickness. It has been shown that for large strains the equivalent von Mises strain, $\varepsilon$, is given by [5]

$\varepsilon=(2 / \sqrt{3}) \operatorname{In}\left[\left(1+\gamma^{2} / 4\right)^{1 / 2}+\gamma / 2\right]$ 
a

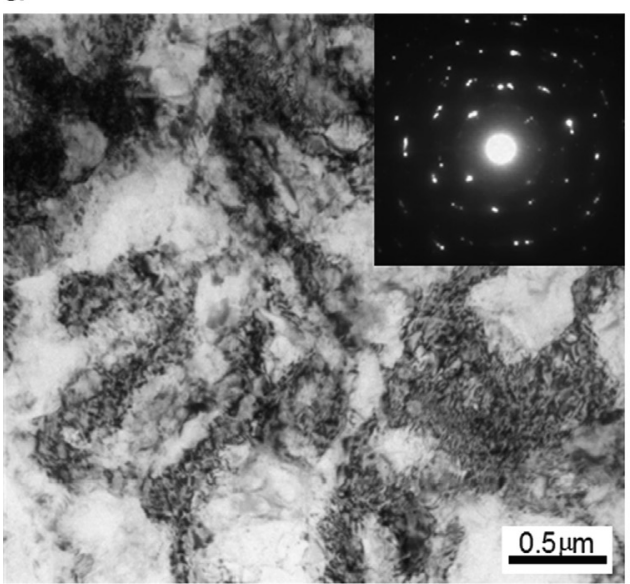

C

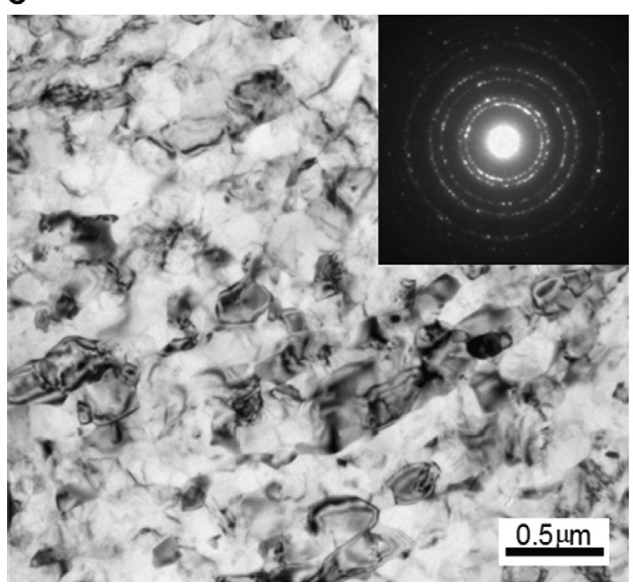

b

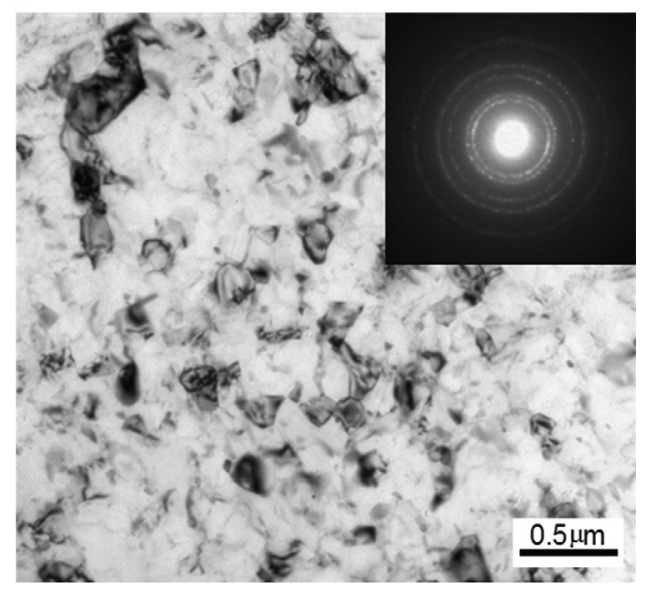

d

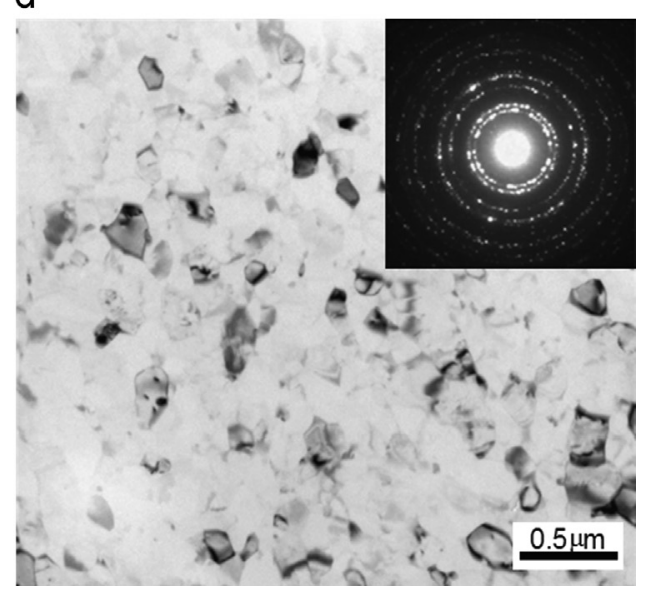

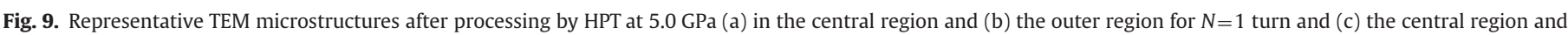
(d) the outer region for $N=5$ turns.

Thus, unlike processing by MAC, in HPT the strain depends critically upon the precise position within the disk.

In this investigation, small TEM disks with diameters of $3 \mathrm{~mm}$ were punched from the HPT disks at the positions shown in Fig. 2(b) and it is reasonable to assume the positions observed by TEM in Fig. 9(b) and (d) at the outer regions of the disks are probably located $\sim 3-4 \mathrm{~mm}$ from the disk centers. Since the initial disk radius and thickness are 5.0 and $0.85 \mathrm{~mm}$, respectively, the equivalent strains imposed at distances from the center of $\sim 3-4 \mathrm{~mm}$ are estimated as $\sim 3.6-3.9$ and $\sim 5.4-5.8$ after processing through 1 and 5 turns, respectively. In the present experiments using MAC processing, it was noted earlier that a strain of $\sim 0.4$ is imposed in each pass so that the total strains are estimated as $\sim 3.6$ and $\sim 6.0$ after 9 and 15 passes, respectively. Thus, the values of the strains in HPT after 1 and 5 turns are very similar to the strains produced in MAC after 9 and 15 passes.

A comparison between Figs. 4(b) and 9(b), where the values of the imposed strain are both $\sim 3.6$, shows significant inhomogeneity after MAC but a very homogeneous structure in the outer region of the disk after HPT. Similarly, a comparison between Figs. 6(a) and 9 (d), where the strains are both close to $\sim 6.0$, shows the presence of more dislocations and subgrain boundaries after MAC but a very homogeneous microstructure after HPT. The favorable characteristics of the HPT process by comparison with MAC is due to the presence of a near uniform simple shear throughout the HPT processing which contrasts with the unsteady deformation in MAC [36]. It is possible in practice to achieve a reasonable level of homogeneity in MAC by introducing an additional annealing treatment as shown in Figs. 5(c) and 6(b) where the samples were annealed for $1 \mathrm{~h}$ at $473 \mathrm{~K}$. However, the resultant homogeneity was achieved after grain growth and the measured final grain sizes in these samples were $\sim 0.59 \mu \mathrm{m}$. By contrast, a higher level of homogeneity may be achieved in MAC by processing through 35 passes at $373 \mathrm{~K}$ as shown in Fig. 7(a) and (b) where the grain sizes were $\sim 0.25 \mu \mathrm{m}$ but again there was significant inhomogeneity. A higher degree of homogeneity was obtained by annealing for $1 \mathrm{~h}$ at $473 \mathrm{~K}$ but, as shown in Fig. 7(c) and (d), this increases the grain size to $\sim 0.5 \mu \mathrm{m}$. By contrast, an average grain size of $\sim 0.25 \mu \mathrm{m}$ was achieved after pressing by HPT for 5 turns as shown in Fig. 9(d).

Thus, the overall conclusion from this research is that processing by MAC leads to a microstructure which is significantly less homogeneous than in HPT. A higher level of homogeneity may be achieved in MAC by using a post-processing annealing treatment but this introduces grain growth so that the final grain sizes are typically about a factor of two larger than in HPT. The larger grain sizes attained in MAC by comparison with HPT are consistent with the higher hardness of $\mathrm{Hv} \approx 160$ achieved in the saturation condition after processing by HPT as shown in Fig. 8 for samples processed through 5 and 9 turns.

It is important to note that all of the HPT processing used in these experiments employed a rotational speed of $1 \mathrm{rpm}$. In practice, however, the rotational speed is essentially insignificant because earlier experiments showed there is only a very minor increase in hardness, and consequentially a very minor decrease in grain size, with increasing rate of rotation in the HPT processing [40].

Finally, it is important to comment that the samples used in HPT processing are generally very small and typically in the form 
of disks having thicknesses of $<1.0 \mathrm{~mm}$. Nevertheless, as described in a recent report [41], there are several new developments in HPT processing including the use of small cylindrical samples $[42,43]$ and the introduction of a continuous HPT processing for use with strip samples and wires [44,45]. These developments attest to the increasing viability of the HPT processing method.

\section{Summary and conclusions}

1. Experiments were conducted on an $\mathrm{Al}-4 \% \mathrm{Cu}$ alloy to provide a direct comparison between the two processing procedures of multi-axial compression (MAC) and high-pressure torsion (HPT). The results demonstrate that processing by HPT is a better procedure for the production of ultrafine-grained materials having a high degree of homogeneity.

2. The experiments show that MAC at room temperature leads to a relatively low level of homogeneity, a high dislocation density and an ill-defined microstructure when conducted at room temperature. Reasonable homogeneity may be achieved, with an average grain size of $\sim 0.5 \mu \mathrm{m}$, by processing by MAC through 35 passes at $373 \mathrm{~K}$ and then annealing for $1 \mathrm{~h}$ at $473 \mathrm{~K}$.

3. Processing by HPT through five turns at room temperature produces a reasonably homogeneous microstructure with a grain size of $\sim 0.25 \mu \mathrm{m}$. The measured Vickers microhardness is $\mathrm{Hv} \approx 160$ after HPT through 5 or more turns and this is higher than the microhardness values recorded when processing by MAC.

\section{Acknowledgments}

This work was supported in part by the National Key Fundamental Research Project of China under Grant no. 012CB619506-2 and in part by the European Research Council under ERC Grant agreement no. 267464-SPDMETALS.

\section{References}

[1] R.Z. Valiev, R.K. Islamgaliev, I.V. Alexandrov, Prog. Mater. Sci. 45 (2000) 103. [2] Y. Huang, T.G. Langdon, Mater. Today 16 (2013) 85.
[3] R.Z. Valiev, Y. Estrin, Z. Horita, T.G. Langdon, M.J. Zehetbauer, Y.T. Zhu, JOM 58 (4) (2006) 33.

[4] R.Z. Valiev, T.G. Langdon, Prog. Mater. Sci. 51 (2006) 881.

[5] A.P. Zhilyaev, T.G. Langdon, Prog. Mater. Sci. 53 (2008) 893.

[6] Y. Saito, N. Tsuji, H. Utsunomiya, T. Sakai, R.G. Hong, Scr. Mater. 39 (1998) 1221.

[7] G.A. Salishchev, S.V. Zherebtsov, S. Yu. Mironov, M.M. Myshlayev, R. Pippan, in: M.J. Zehetbauer, R.Z. Valiev (Eds.), Nanomaterials by Severe Plastic Deformation, Wiley-VCH, Weinheim, Germany, 2004, p. 691.

[8] A.P. Zhilyaev, B.K. Kim, G.V. Nurislamova, M.D. Baró, J.A. Szpunar, T.G. Langdon, Scr. Mater. 46 (2002) 575.

[9] A.P. Zhilyaev, B.K. Kim, J.A. Szpunar, M.D. Baró, T.G. Langdon, Mater. Sci. Eng. A 391 (2005) 377.

[10] J. Wongsa-Ngam, M. Kawasaki, T.G. Langdon, J. Mater. Sci. 48 (2013) 4653.

[11] S.V. Zherebtsov, G.A. Salishchev, R.M. Galeyev, O.R. Valiakhmetov, S.Y. u. Mironov, S.L. Semiatin, Scr. Mater. 51 (2004) 1147.

[12] Y.J. Li, W. Blum, Phys. Status Solidi A 202 (2005) R119.

[13] Y.J. Li, X.H. Zeng, W. Blum, Mater. Sci. Eng. A 483-484 (2008) 547.

[14] A. Kundu, R. Kapoor, R. Tewari, J.K. Chakravartty, Scr. Mater. 58 (2008) 235.

[15] A. Rezaee-Bazzaz, S. Ahmadian, Mater. Des. 34 (2012) 230.

[16] W.C. Liu, M.B. Chen, H. Yuan, Mater. Sci. Eng. A 528 (2011) 5405.

[17] B. Cherukuri, T.S. Nedkova, R. Srinivasan, Mater. Sci. Eng A 410-411 (2005) 394.

[18] B. Cherukuri, R. Srinivasan, Mater. Manuf. Processes 21 (2006) 519.

[19] Z. Liu, X. Chen, X. Han, Y. Gu, Mater. Sci. Eng. A 527 (2010) 4300.

[20] A.K. Parimi, P.S. Robi, S.K. Dwivedy, Mater. Des. 32 (2011) 1948.

[21] Z. Liu, S. Bai, X. Zhou, Y. Gu, Mater. Sci. Eng. A 528 (2011) 2217.

[22] R.B. Figueiredo, P.R. Cetlin, T.G. Langdon, Mater. Sci. Eng. A 528 (2011) 8198.

[23] R.B. Figueiredo, P.H.R. Pereira, M.T.P. Aguilar, P.R. Cetlin, T.G. Langdon, Acta Mater. 60 (2012) 3190.

[24] M. Kawasaki, T.G. Langdon, Mater. Sci. Eng. A 498 (2008) 341.

[25] C. Xu, Z. Horita, T.G. Langdon, Acta Mater. 55 (2007) 203.

[26] C. Xu, Z. Horita, T.G. Langdon, Acta Mater. 56 (2008) 5168.

[27] M. Murayama, Z. Horita, K. Hono, Acta Mater. 49 (2001) 21.

[28] C. Xu, M. Furukawa, Z. Horita, T.G. Langdon, Mater. Sci. Eng. A 389 (2005) 66.

[29] J. Wang, Z. Horita, M. Furukawa, M. Nemoto, N.K. Tsenev, R.Z. Valiev, Y. Ma, T. G. Langdon, J. Mater. Res. 8 (1993) 2810.

[30] J. Wang, Y. Iwahashi, Z. Horita, M. Furukawa, M. Nemoto, R.Z. Valiev, T. G. Langdon, Acta Mater. 44 (1996) 2973.

[31] R. Valiev, Nat. Mater 3 (2004) 511.

[32] S. Sabbaghianrad, M. Kawasaki, T.G. Langdon, J. Mater. Sci. 47 (2012) 7789.

[33] J. Wongsa-Ngam, M. Kawasaki, T.G. Langdon, J. Mater. Sci. 47 (2012) 7783.

[34] A. Vorhauer, R. Pippan, Scr. Mater. 51 (2004) 921.

[35] F.A. Mohamed, S.S. Dheda, Mater. Sci. Eng. A 558 (2012) 59

[36] V.M. Segal, Mater. Sci. Eng. A 338 (2002) 331.

[37] T.G. Langdon, Mater. Sci. Eng. A 462 (2007) 3

[38] S.V. Harren, H.E. Deve, R.J. Asaro, Acta Metall. 36 (1988) 2435.

[39] R.Z. Valiev, Y.V. Ivanisenko, E.F. Rauch, B. Baudelet, Acta Mater. 44 (1996) 4705

[40] P. Serre, R.B. Figueiredo, T.G. Langdon, Mater. Sci. Eng. A 528 (2011) 3601.

[41] R.Z. Valiev, T.G. Langdon, Metall. Mater. Trans. A 42 (2011) 2942.

[42] G. Sakai, K. Nakamura, Z. Horita, T.G. Langdon, Mater. Sci. Eng. A 406 (2005) 268.

[43] R. Pippan, S. Scheriau, A. Hohenwarter, M. Hafok, Mater. Sci. Forum 584-586 (2008) 16.

[44] K. Edalati, Z. Horita, J. Mater. Sci. 45 (2010) 4578

[45] K. Edalati, Z. Horita, J. Mater. Sci. 47 (2012) 478. 